bed on a low diet vomiting persisted, in a few days marked stupor became evident, and the case for a time looked like one of cerebral origin. The urine was again tested with negative results. The patient became very weak, her breath was short, and she was apathetic. Her breath was very foul and her tongue was thickly farred, flabby, and large; the lips were full and livid, the face was decidedly puffy, and the bowels were very costive. Increasing signs of mental failure, loss of memory, stupor and giddiness with melancholia, and falling out of her hair, associated with a bruit about the aorta, pointed to sypbilis, and iodide of potassium was tried but without avail. The probability of myxœdema being the fons et origo mali next suggested itself and a five-grain tabloid of thyroidin; to be taken twice daily, was prescribed with the result that in three days an obvious change for the better had. set in, the patient saying, to use her own words, that "she did not feel so dull." She also began to sleep better, was more inclined for conversation, and she looked decidedly better. The thyroid gland was felt for but could not be made out. The patient for the first few weeks was kept in bed and the dose of thyroidin was gradually increased from two to four tabloids a day and saline aperients were given. This line of treatment was persisted in for six months, the patient, though inclined to shortress of breath and aching of the legs, eventually being able to walk up to my house in very fair health and spirits to see me. Her pulse had become of good volume and tension, the cedema of the feet had disappeared, her face and lips were but very little swollen, and having so far recovered she left off the treatment. A year has passed by and I have just seen her again. Although she is able to perform her household duties, if she is not hurried, she is obviously in need of thyroid tablets, as she has marked dyspnoea, swelling of the ankles, puffiness of the face, and disinclination for much mental effort. The instructive points in this case from a diagnostic standpoint are, I consider, (1) its resemblance to Bright's disease; (2) symptoms which seemed to point to brain disease; and (3) signs of atheroma of the aorta ; in reality, however, myzcedema was the cause of her illness. The sloppiness of the conjunctivæ referred to by Chapman ${ }^{1}$ as due to the presence of mucin, and diagnostic of myxoedema when no albumin is found in the urine, was well marked when I saw my patient last.

Freat Yarmouth.

\section{Clinital êtrotes:}

\section{MEDICAL, SURGICAL, OBSTETRICAL, AND THERAPEUTICAL.}

\section{NOTE ON A QUIET FEFUSION INTO THE KNEE-JOINTS.}

By J. Lioner Strettron, L.R.C.P. Lond., M.R.C.S. Eng., SENIOR SURGEON TO THE KIDDERMINSTER INFIRMARY AND CHILDREN'S HOSPITAL.

IN the report of a very interesting lecture on the above subject by Mr. William H. Bennett contained in THE LAANCET of Feb. 23rd, p. 527, it is stated that "it is limited to girls and women and is always associated with menstrual irregularity or uterine trouble." As I have met with several cases which appear to be exactly similar to those described save for the fact that they occurred in males, perhaps it may be of interest to mention them. I have only exact notes of the last case which I append.

The patient, a boy, aged 11 years, was brought to the hospital on Oct. 4th complaining of swelling of the right knee which had existed for several weeks. There was no history of injury and his family were all healthy-no taberculous or syphilitic mischief. He walked into the consulting-room without difficulty and did not complain of pain. On examination the right knee was found to be swollen and contained a considerable amount of fluid. When standing the gravitation of the fluid to the lower

1 Medical Record, Oct. 21st, 1899. anterior part of the joint was well marked. On comparing it with the other knee effusion was found in that also but not so much in amount. The circumference of the right knee was $13 \frac{1}{2}$ inches and that of the left 12 inches. There had been no injury and nothing could be elicited to account for the condition. There was no increase of temperature or other constitutional trouble. He was put to bed and the knees were kept on back splints with lead lotion, \&c. He was blistered, treated with Scott's dressings and plaster-ofParis cases. Internally he was given a course of iodide of potassium, sodium salicylate, and tonics, but all to no avail, as after two months his condition remained unaltered. $\mathrm{He}$ was put in plaster-of-Paris cases and allowed to get up and walk about. He went home and when he reported himself a month later the effusion had very much diminished. He was ordered to have his limbs and knees massaged and to leave off the cases. When seen a few days ago, six months since his admission, the effusion had entirely disappeared and he was able to walk about without causing any swelling.

Kidderminster.

\section{NOTES ON TWO SUOCESSFUL CASES OF OVARIO-} TOMY WITH COMPLICATIONS, ILLUSTRATING THE VALUE OF SALINE FLUSHING.

By E. J. Trevor Jones, M.D. Brux., M.R.C.S. Eng., L.R.C.P. LOND.,

SURGEON TO THE ABERDARE COTTAGE HOSPITAL.

CASE 1.-The patient, a married woman, aged 32 years, consulted her medical attendant nine months after marriage because she was alarmed at the rapidly increasing size of her abdomen-a condition which was at first thought to be pregnancy. I saw her in consultation with Mr. F. Finney and an ovarian cyst was diagnosed. She was admitted to the Aberdare Cottage Hospital in June, 1900. On opening the abdomen the cyst was found to be unusually tense and large, with many adhesions. On introducing the trocar the tense cyst ruptared and in spite of careful packing mach of the contents escaped into the peritoneal cavity. After emptying the cyst the adhesions, which were unusually numerous in a cyst only seven months old, were ligatured, but the omentum was found to be adherent to the intestine. The adhesions were dissected off and part of the omentum was ligatured and taken away. The abdomen was then thoroughly irrigated with warm saline solution (one and a half drachms of chloride of sodium to the pint of sterilised water). When the fluid had returned clear the abdomen was united with silkworm.gut sutures through all the coats. The cavity was left filled with the saline solution and the wound was dressed in the usual way, but without drainage. A slight rise of temperature occurred on the first and second nights, after which the patient made a good lesovery.

OASE 2 . -The patient, aged 66 years, unmarried, had since the climacteric noticed a gradually increasing tumour of the abdomen which was diagnosed as an ovarian cyst. The operation took place in the patient's home on August 12th, 1899. A three-inch incision was made and the trocar was introduced in the ordinary way. On emptying the cyst by pressure it ruptured and some of the contents escaped into the peritoneal cavity. In this case the adhesions were few and the wall of the cyst seemed to be undergoing degenerative changes. On introducing the hand to ligature the pedicle a moderately-sized tumour was detected which on examination proved to be a uterine fibroid. The abdominal cavity was thoroughly irrigated with the sterilised saline solution and the abdomen was treated as in the previous case, leaving the cavity of the peritoneum filled with the solution. The patient made an uninterrupted recovery and has since enjoyed good health.

I have thought it worth while to put on record my experience of the value of irrigation with saline solution and the retention of the solution in the abdomen. The solution seems to me to act by absorbing any septic matter that may remain in the peritoneal cavity. I also noticed that these two patients suffered very little from thirst after the operation, which fact may be accounted for by the absorption of flaid from the abdomen.

Aberdare. 